\title{
Noncrystal Ionic Model for Silica Glass
}

\author{
Leroy W. Tilton
}

\begin{abstract}
A model was constructed of pentagonal rings of symmetrical tetrahedra so connected that all five silicons lie in one plane and all angles $\mathrm{Si}-\mathrm{O}-\mathrm{Si}$ approximate $180^{\circ}$. From an initial tetrahedron the rings extend in six directions to include its six edges, and in the resulting three-dimensional network each ring forms a common interface between dodecahedral cages which necessarily have fivefold symmetry. Such symmetry is incompatible with formation of a crystal lattice and thus the structure can be extended in three dimensions only to a very limited degree and with unavoidable stress and distortional strain. A stressed network cluster of such dodecahedral cages is here called a vitron.

If the scale in this model for silica glass is taken as $1.6 \mathrm{~A}$, from silicon to oxygen, the model is found to be in accord with other radial distances computed from diffraction data and the density is correct within 10 percent. The apertures of the pentagonal interfaces are of suitable size to explain data on the diffusion of noble gases through silica. Shared penta faces and intermittent oxygen bridges connect neighboring vitrons and constitute an interstitial tissue of relatively weakened structure that accounts for the observed low tensile strengths of silica glass and provides channels for viscous flow.

The proposed cages would be less pliable at low temperatures and so the interstitial tissues between vitrons should expand in volume on cooling. This "negative" expansion would counter the normal expansion and account for the known extremely small (net) expansivity of silica glass. The accompanying changes in strength and volume of the glass at its weakest places, the interstitial tissues, can account for a number of known "anomalies" in thermal behavior of silica glass with respect to its volume, compressibility, elastic moduli. and viscous flow.

The vitron concept reconciles the crystallite and the network theories of glass by proposing nuclei that cannot grow extensively and a distribution of localized stresses that may constitute an acceptable degree of randomness and provide effective modulations in continuity. This concept of definite but limited microregularity in structure suggests that other noncrystal symmetries should be studied for possible interest in other fields such as liquids and high polymers.
\end{abstract}

\section{Introduction}

Evidence from X-ray data shows that glasses and even liquids have some degree of ordered arrangement, although it definitely differs from that in crystals. Also, in studies of liquids and plastics it is recognized that limited ordered arrangements, often called "crystallinity," can exist without formation of macroscopic crystals. Under these circumstances two important theories of the glassy state have developed. The crystallite theory was stated by Randall and coworkers [1] ${ }^{1}$ in 1930. The presence of submicroscopic crystallites or crystalline nuclei in very large numbers in undercooled glasses was inferred, soon after the X-ray reports published by Clark and coworkers [2] in 1929, in order to account for the breadth of the observed diffraction rings. The acceptance of this idea proved difficult because many investigators found no evidence of a normal growth in the size of such crystallites under conditions that do promote growth whenever nuclei of crystals are known to be present.

The network theory resulted largely from the work of Zachariasen [3] and his coworkers in the field of chemical crystallography, and some associated ideas were more definitely formulated by Warren [4] and his coworkers in analyzing their X-ray data to establish interatomic distances and in interpreting the breadth of the diffraction rings from glass as contrasted with the well-defined rings from crystals. This continuous random network theory of glasses has been stimulating and fruitful in the field of inorganic glasses. A very limited degree of shortrange order of arrangement of nearest neighbors and next nearest neighbors among the ions in glass is now definitely determinable by X-ray and electron diffraction, but the unbroken continuity and the very considerable randomness that is often assumed at longer distances seem incompatible with some experimental data.

W. A. Weyl [5] has considered that the network theory "in its present form" is not satisfactory to account for some existing data, and he wrote a paper "to show the need for a revision in our present approach to the constitution of glasses." In this paper he says: "One of the rost important properties of glass, its mechanical strength, seems to resist all attempts to unveil its secrets"; again, "We have no plausible explanation yet for the thermal expansion of glasses as a function of their composition"; also, "It is customary to talk about 'flow units' in describing viscosity . . about association-disassociation equilibria in any discussion of the effects which thermal history has upon the properties of glass. . . Nobody, however, has yet given an accurate description of a 'flow unit' . . . nor presented a reasonable concept of the unit which disassociates.

Confining attention to the simple case of silica glass, one finds numerous and well-established data that characterize this material as unusual or even unique in respect to some of its properties, such as expansibility, compressibility, rigidity, and variations therein as effected by temperature and pres- 
sure. These relationships have been discussed in detail by Babcock, Barber, and Fajans [6], who say, ". . . Use of the random network theory . . . has in general been unsuccessful in interpreting the properties of silicate glasses. . .." Spinner [7], who measured elastic moduli at elevated temperatures, says: "It seems clear that. . . the usual picture of the structure of silica, as a random 3-dimensional network of $\mathrm{SiO}_{4}$ tetrahedra, needs to be amended or modified to explain the various phenomena associated with the material."

Evidence of somewhat long-range order in silica glass was found by Melkonian [8], who wrote, "Fused quartz . . . was expected not to show microcrystalline interference effects because of its supposed lack of long-range crystalline structure. Thus, it was expected to show a transmission nearly independent of neutron energy and hence to be suitable for use as a secondary standard . . . Fairly large interference effects are evident which make this particular sample useless as a secondary standard." In accord with this, Milligan, Levy, and Peterson [9], in their neutron-diffraction studies on vitreous silica, found 5 or 6 well-defined maxima and 4 or 5 others that were less well defined. Hoffman and Statton [10] used the low-angle scattering of X-rays in glass and found evidence of spacing in fused silica of $30 \mathrm{~A}$ or larger. In brief, there is evidence that the short-range order should be extended at the expense of longer-range randomness.

In order to study possible extensions of the accepted short-range order in simple silica glass, a three-dimensional model was constructed starting with silicon-oxygen tetrahedra connected at their corners by the sharing of their oxygens. This model, described in this paper, gives the correct density for silica glass within 10 percent, provided the scale is determined in accord with the established average distance of $1.6 \mathrm{~A}$ from silicon to oxygen as found [11] for silica and the silicates. It will be shown that the interatomic distances are in very good agreement with all radial distances computed from X-ray, electron, and neutron-diffraction data, and the apertures are of suitable size to explain Norton's [12] data on the diffusion of noble gases through silica.

The proposed model is a network of pentagonal rings of tetrahedra with 12 -sided regular cavities, as in figure 1 (approximate diameter, locus of silicon centers, $8 \mathrm{~A}$ ). It cannot grow extensively without peripheral tensional distortions that ultimately prevent further maintenance of the silicon-oxygen bonds. A cluster of such dodecahedral cavities or cages, such as shown in figure 2 , is here called a VITRON, a new concept that may have application in other fields such as rheology and high-polymer studies where noncrystal order may be evidenced.

Aside from the fundamental conceptual difference between a vitron and a crystallite, the proposed model does in many respects accord well with the crystallite hypothesis. It is also essentially the network hypothesis with a modulation of its continuity,

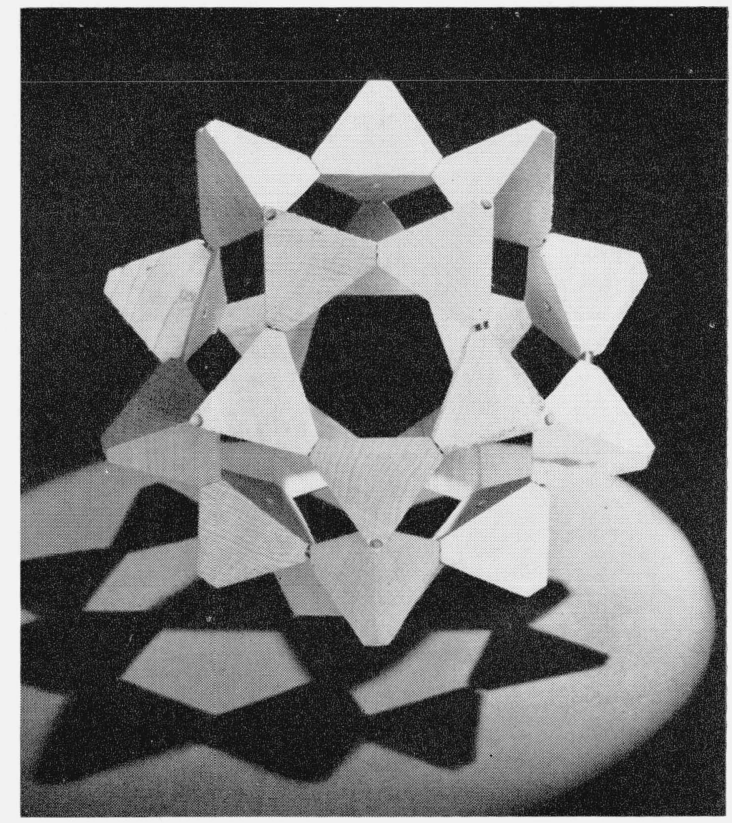

Figure 1. View along fivefold axis of a single-element vitron constructed of 20 tetrahedra representing 20 silicon atoms at their centers and 30 oxygen atoms at their connected corners.

(Twenty outer corners are available for attachments.) Only one-quarter of each $\mathrm{Si}$ and one-third of each (connecting) $\mathrm{O}$ belong to this cage as an element or unit of a larger vitron. In other words, $5\left(\mathrm{SiO}_{2}\right)$ constitute a single element or cage of a vitron on a continuum basis.

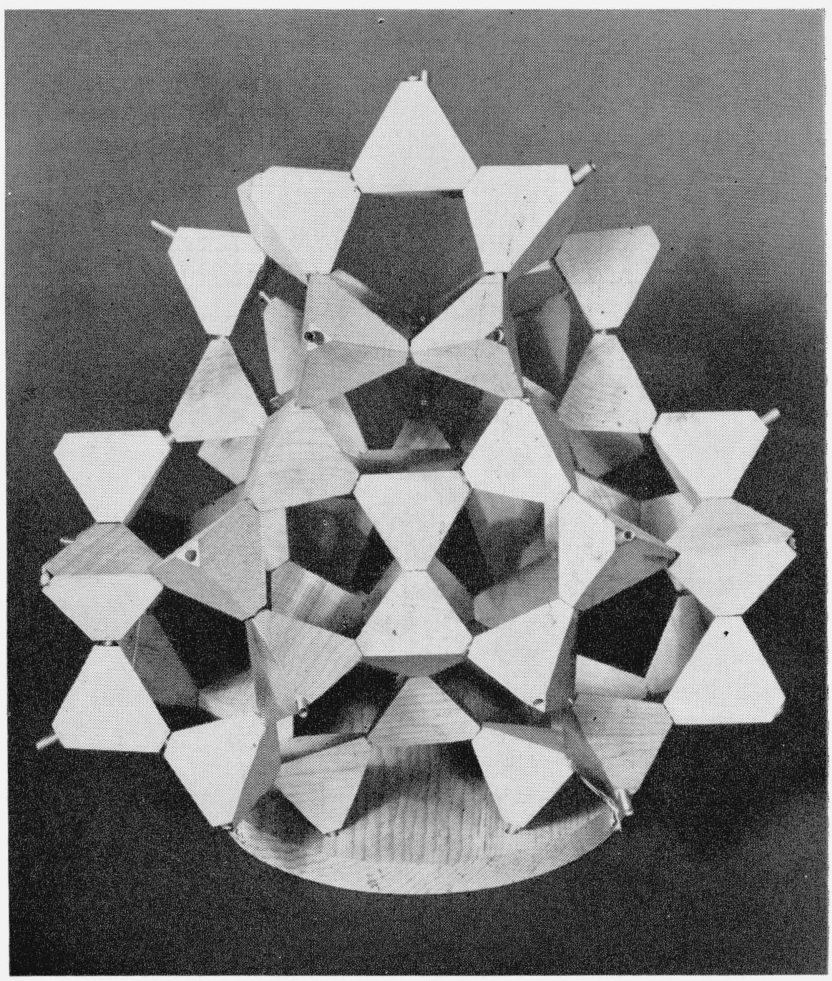

Figure 2. Off-axis view of completed four-element vitron (type 4 , tetrahedral).

Coiled wire springs indicate extra $\mathrm{O}$ - charges and vacant tetrahedral corners indicate $\mathrm{Si}+$ charges available for attachments to other vitrons by oxygen bridges. At center foreground is a reentrant three-face that can unite with another vitron At center foreground is a reentrant three-face that
presenting a convex three-face. See appendix. 
a reduced randomness, and an added feature of localized stress distribution.

Partial unions and attachments between adjacent vitrons form interstitial channel tissues that are less regular and weaker than the intravitron structure. These tissues, together with the localized stress distributions within vitrons, are important in qualitative explanations of the peculiar effects of heat and pressure on the volume characteristics of silica glass; also in understanding viscous flow and conductance. Preliminary studies indicate that the proposed model will permit semiquantitative inferences concerning possible cavity-saturation limits for nonsilica that correlate with property-composition curves of solubility, chemical attack, volatilization, and specific volume for binary alkali-silicate glasses.

\section{Pentagonal Dodecahedral Model}

Silica glass is here considered to have a high-temperature arrangement of connected silicon-oxygen tetrahedra that has been cooled so quickly that the conditions at high temperature have been "frozen" by rapid increases in rigidity. It is therefore assumed that the connected tetrahedra will have minimum density, and this can obtain only if the bonds form angles $\mathrm{Si}-\mathrm{O}-\mathrm{Si}$ of $180^{\circ}$ and the rings, if any, are circular and planar so that the tetrahedra can have maximum distention. (See fig. 3.) Under these circumstances, probability greatly favors the formation of pentagonal rings, as mentioned by Poncelet [13], because the interior angle of a regular tetrahedron is $109^{\circ} 28^{\prime}$ and differs so little from $108^{\circ}$, the interior angle of a regular pentagon.

Growth of this structure of minimum density proceeds uniquely in 6 directions from an initial tetra- hedron to form a network containing dodecahedral holes or cavities, each separated from its 12 somewhat-distorted neighboring cavities by 12 planar interfaces of very slightly stressed penta rings. An important property of this model is its many axes, 15 of twofold, 10 of threefold, and 6 of fivefold symmetry. Each of the 15 twofold axes makes an angle of $36^{\circ}$ with each of its 4 neighbor axes, and similarly the 10 axes are equidistributed at angles of $41^{\circ} 48^{\prime}$ and the 6 axes at $63^{\circ} 26^{\prime}$. These features mean close relation to crystal symmetry and a high probability of approximate alinement of different portions of the structure even if separated by less well alined interstitial regions or tissues.

The most important property of this proposed model is its fivefold symmetry, which precludes formation of crystals. Just as penta tiles fail where hexagons succeed in covering a floor, so do regular penta dodecahedra fail to fill space completely and extensively. The interior dihedral angle of a dodecahedron is, however, $116.6^{\circ}$, and thus not far from $120^{\circ}$, which would be exactly right for filling space without stress and distortions. If one regular dodecahedron is attached or joined on each face to 12 like structures, none in the outer shell can touch any of its 5 neighbors. By radial compression these neighbors may meet and the requisite tangential tension in the peripheral bonds may not be excessive for the first shell. Further increase in cluster size by the addition of 32 cages in the second shell would require much higher tensions in the outermost bonds, and some defective attachments or broken bonds might result in order for bonds to hold elsewhere on the periphery. Thus the great strength of the silicon-oxygen bond is the factor that should cause, and vet automatically limit, the growth in size of

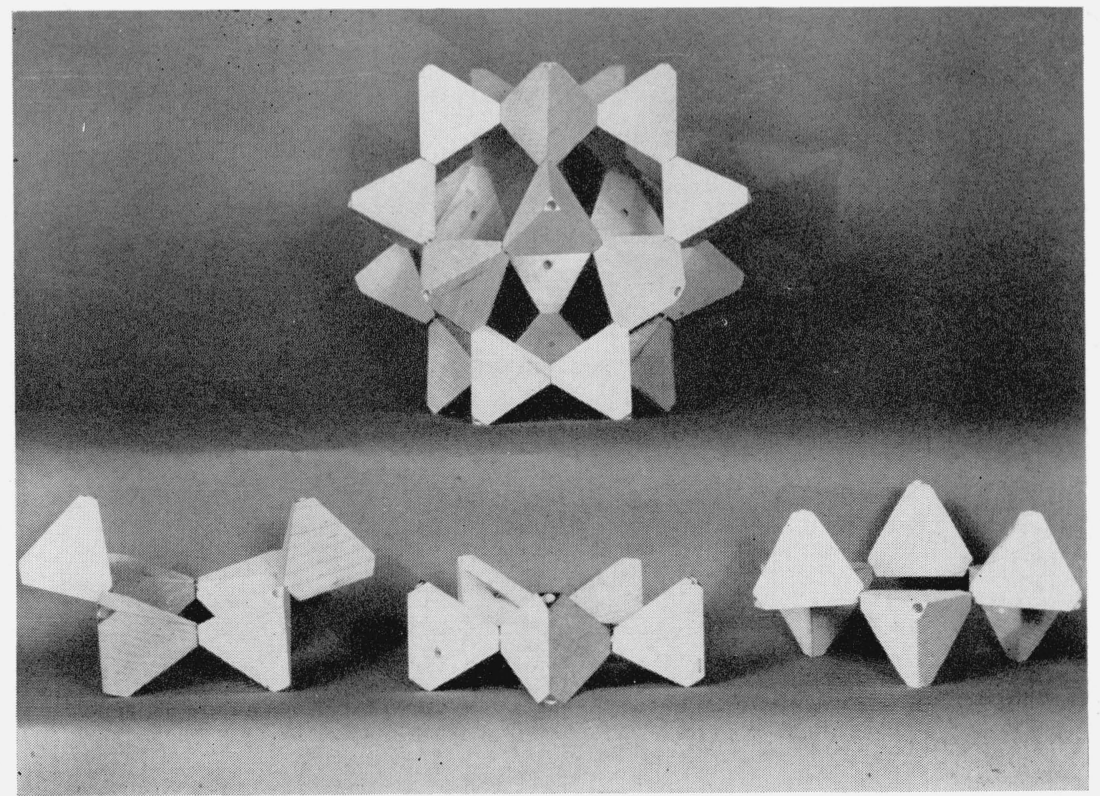

Figure 3. View of regular pentagonal dodecahedral cage formed of planar pentagonal rings of tetrahedra as shown at lower center.

The high-temperature low-density planar ring proposed for silica glass contrasts with the nonplanar hexagonal elemental rings in the denser silicas tridymite (left) and cristobalite (right). 
vitrons. The automatically limited ability to grow, and a distribution of stresses localized and balanced within each vitron, are features that may distinguish a vitreous substance from a crystal.

Silicon ions are situated at each of the 20 vertices of a pentagonal dodecahedron, and oxygen ions at the midpoint of each of the 30 edges. An isolated unit of this sort would consist of 20 silicon atoms and 30 of oxygen with 20 plus charges, and thus be represented as $\left(\mathrm{Si}_{20} \mathrm{O}_{30}\right)^{20+}$. A cluster of 7 such units is $\left(\mathrm{Si}_{85} \mathrm{O}_{145}\right)^{50+}$ but it is decidedly nonspherical. With 13 such cages there is again an approximation to sphericity with a diameter of $20 \mathrm{~A}$ (see fig. 7). This 13-cage cluster can be represented as $\left(\mathrm{Si}_{130} \mathrm{O}_{230}\right)^{60+}$, and the plus charges are distributed over the whole surface in 12 pentagonal groups. Upon addition of the next shell, consisting of 32 dodecahedral cages, to form a 45-cage cluster the diameter increases to $30 \mathrm{~A}$ and the formula is $\left(\mathrm{Si}_{330} \mathrm{O}_{620}\right)^{80+}$. The plus charges indicate the degree of attachability of these vitrons to their neighbors through oxygen bonds. In addition, or alternately, they may actually unite or grow together with neighbors to limited extents, as further discussed in the appendix.

Figures 4, 5, and 6 (also 9 and 10) are helpful for visualizing the arrangement of atoms in the proposed model. With dimensions based on the average $\mathrm{X}$-ray datum of $1.60 \mathrm{~A}$ for the Si-O distance (between centers), an element or cage can be inscribed in a sphere of $9 \mathrm{~A}$ diameter, and a sphere of $7 \mathrm{~A}$

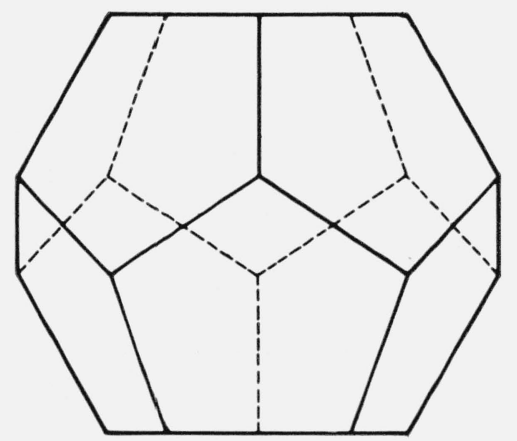

Figure 4. Schematic projection of pentagonal dodecahedral element of a vitron on plane perpendicular to two of its pentagonal faces.

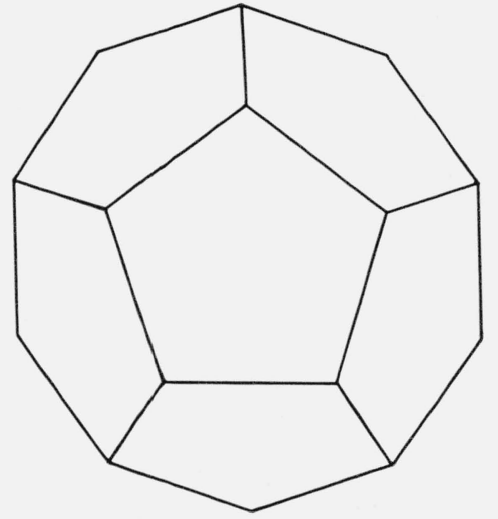

Figure 5. Schematic dodecahedral element viewed along one of its six axes of fivefold symmetry through pairs of opposite and parallel faces. diameter can be inscribed inside a cage. Only a central cage of a vitron can be truly regular and symmetrical. The surrounding cages must be deformed in order to contact their neighbors. Hence it is interesting to recall that Warren [14] estimated $8 \mathrm{~A}$ as the maximum dimension of the region of periodicity in fused quartz, and that Valenkov and Poray-Koshitz [15] estimated $12 \mathrm{~A}$ as the extent of perfect order, with surrounding regions of intermediate degree of order. Also, measurements on thermal conduction in glasses have made it possible, as shown by Kittal [50], to estimate $8 \mathrm{~A}$ as the mean free path distance ovor which plane elastic heat waves (phonons) may travel in silica glass at room temperatures before distortional scattering.

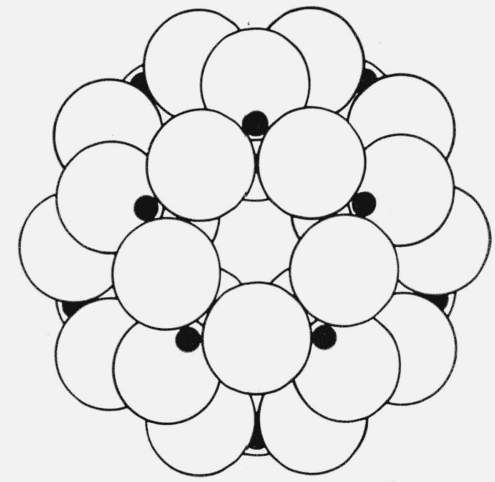

Figure 6. Dodecahedral element viewed along one of its six axes of fivefold symmetry.

Some outer atoms are omitted.

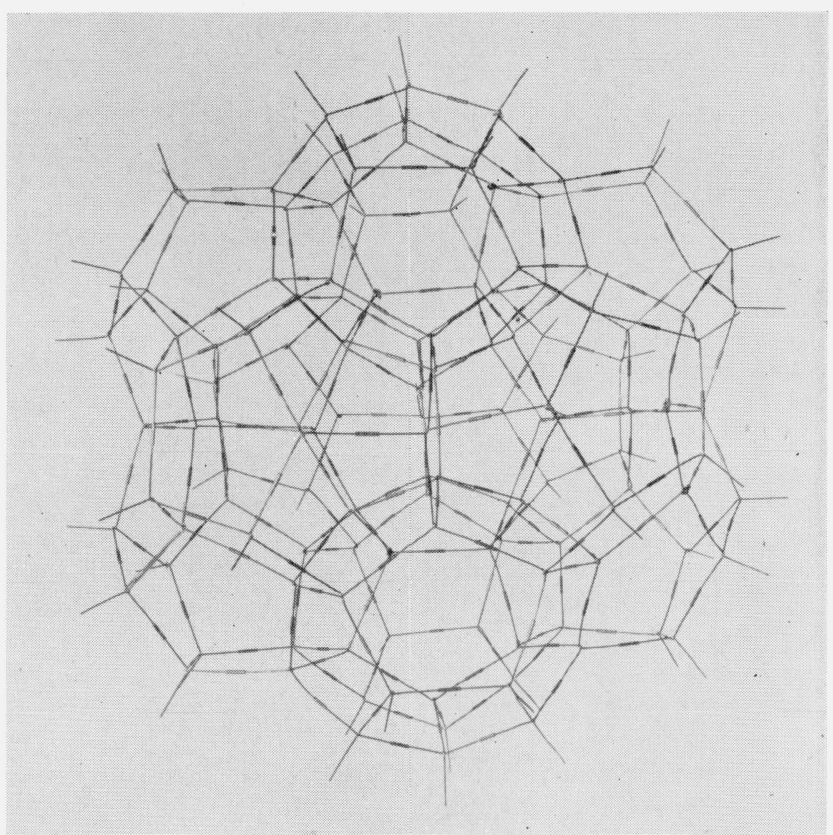

Figure 7. View along one of 15 identical twofold axes of symmetry of a 13-element vitron (type 1, spherical).

In this model a tetrahedron is represented by two wires bent at an angle of $109.5^{\circ}$ and soldered at their symmetrical crossing to represent silicon. Oxygen is represented by friction-tight couplings. Two other axes of twofold symmetry lie normally to the line of sight. 


\section{Density of Vitreous Silica}

On the basis of unlimited continuity of the proposed structure for silica glass (as if it were extensible without distortion from micro to macro proportions) there would be $5\left(\mathrm{SiO}_{2}\right)$ per dodecahedral unit of volume, and the density is computed from the molecular weights and cage dimension as

$$
d=\frac{5 \times 60.06}{7.663 N l^{3}},
$$

where $N$, Avogadro's number, is $6.023 \times 10^{23}$ molecules per mole and $l$ is the length of an edge of the dodecahedron expressed in centimeters. The volume of one dodecahedral cage is $7.663 l^{3} \mathrm{cu} \mathrm{A}$ and the computed density of fused silica would be $1.949,1.986$, or $2.023 \mathrm{~g} / \mathrm{cm}^{3}$ according as $l / 2$, the Si-O distance, is assumed from X-ray data as $1.61,1.60$, or $1.59 \mathrm{~A}$. These densities are only 10 percent lower than 2.20 , the density of silica glass from room temperatures to $1,400^{\circ} \mathrm{C}$ or higher.

Possibly such low values of the density of fused silica may be approximated in its liquid state at very high temperatures at or near vitron formation. However, the continuity above assumed cannot exist when silica is cooled, because of the noncrystal nature of its structure with fivefold symmetry and the distortions and fissuring inherent in the process of its macro-growth. The tensions induced in the outer bonds, as the vitrons grow in volume, probably lead to some tangential rarefactions and radial compressions as successive shells are built up on vitrons, and the net effect on the average density, not readily evaluated, may be densification mainly because of decrease in volume as the empty cages are flattened by slight changes in bond angles.

Aside from densification through such a decrease in the unit volumes of the outer and distorted cages of vitrons, there would be a variation in the effective density of vitrons according to their size. The internal portion of each elemental volume or cage contains $5\left(\mathrm{SiO}_{2}\right)$ in $251 \mathrm{~A}^{3}$, and the volume of the atoms is only about $95 \mathrm{~A}^{3}$. Outside an isolated small vitron there may be almost as many atoms as inside. The outside atoms must project into interstitial or channel tissues and add proportionately more to the mass of the vitron than they do to its effective volume. A useful and attachable elemental unit volume to consider is $\left(\mathrm{Si}_{10} \mathrm{O}_{20}\right)$ with $10+$ and $10-$ associated charges. Such a unit with balanced charges is attachable to a like unit to form the attachable twocluster vitron $\left(\mathrm{Si}_{20} \mathrm{O}_{40}\right)^{15+, 15-}$. The unit $\left(\mathrm{Si}_{10} \mathrm{O}_{20}\right)^{10+, 10-}$ has $5\left(\mathrm{SiO}_{2}\right)$ inside and the same number outside its $251 \mathrm{~A}^{3}$ limits. Considering this unit as a singlecluster vitron, the outside atoms would extend into the surrounding interstitial tissues, which must have a minimum thickness of $1.6 \mathrm{~A}$ (the Si-O distance). From the single-cage volume of $251 \mathrm{~A}^{3}$ one computes the diameter of an equivalent sphere as $7.8 \mathrm{~A}$, and 9.4 A would be the effective diameter of the onecluster vitron including its minimum share of neighboring interstitial connective tissues. The computed maximum effective density is then 2.3 , instead of 2.0

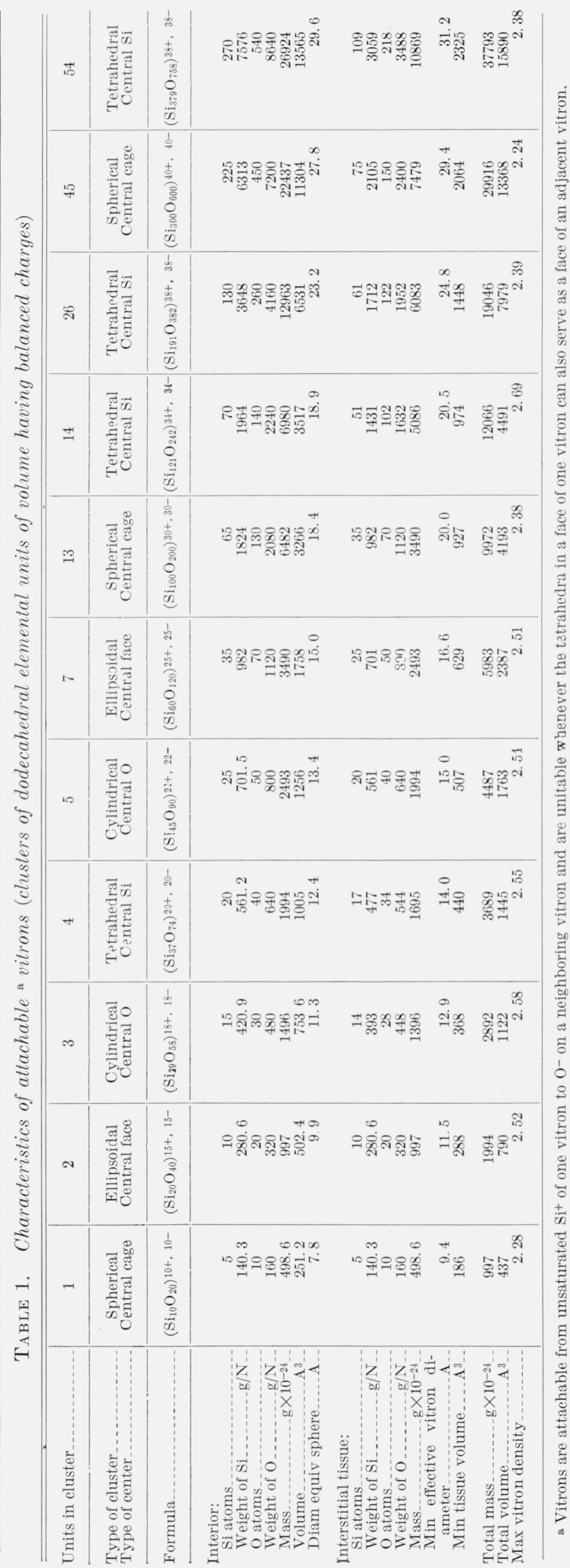


as computed on the continuum basis. In other words, the interstitial tissues can be denser than the internal portions of vitrons, even if the bonds therein be fewer, less regular, or unconnected, because these tissues cannot share in the extreme degree of rarefaction in space that characterizes silica in dodecahedral structure.

The results of a study of vitrons of various sizes are given in table 1 . It is considered that at the high temperatures of formation the vitrons grow simultaneously in situ throughout a melt and that smaller vitrons will grow in every sizable region that might otherwise remain undeveloped between larger vitrons. All these vitrons of various sizes and perhaps of somewhat irregular shapes can be actually, if imperfectly, united with neighbors at some common interfaces, and by multiple oxygen bridges across intervening channels can be more or less securely attached to each other.

It appears from table 1 that the maximum effective density exceeds the constant internal density of 2.0 by various amounts depending on the size of the vitron and the degree in which its shape approximates the sphericity assumed in the estimates. It will be evident that nonspherical clusters must have greater peripheral areas than assumed, and hence their estimated effective densities must be too high. However, there are several clusters for which the estimated maximum density is less than 10 percent above 2.20 , the known density of silica glass. Further details concerning vitrons and their aggregation are given in the appendix.

\section{Diffusion of Gases in Silica Glass}

An important feature of a model for the network of glasses with high silica content is the minimum or limiting aperture through which atoms must pass when gases diffuse through glasses and when ions migrate under the influence of an electrical field.

Experiments concerning the diffusion of gases through glass may not, in general, be considered solely on a mechanical basis, as a process of the squeezing of molecules through molecular holes or cracks. The more reactive hydrogen diffuses slower than the inert helium when oxygen is present, but their rates are about the same in a solid without oxygen anions.

However, in the case of diffusion of noble gases it is probably valid to consider dimensions as much more important than chemical nature, and in seeking to understand the very marked diminution in the permeability of silica glass to argon, in comparison with that for neon, it seems tenable and sufficient to regard size only. As measured by Norton [12], the diffusion rate for neon with atom diameter $2.4 \mathrm{~A}$, was found to be more than 100,000 times as high as the rate for argon, atom diameter $3.2 \mathrm{~A}$. Figure 8 shows how well the penta faces of the elements of vitrons in silica are adapted to pass neon and smaller atoms such as deuterium, hydrogen, and helium, but obstruct argon, oxygen, and nitrogen, which have larger diameters.

Norton found, also, that the rates for helium at

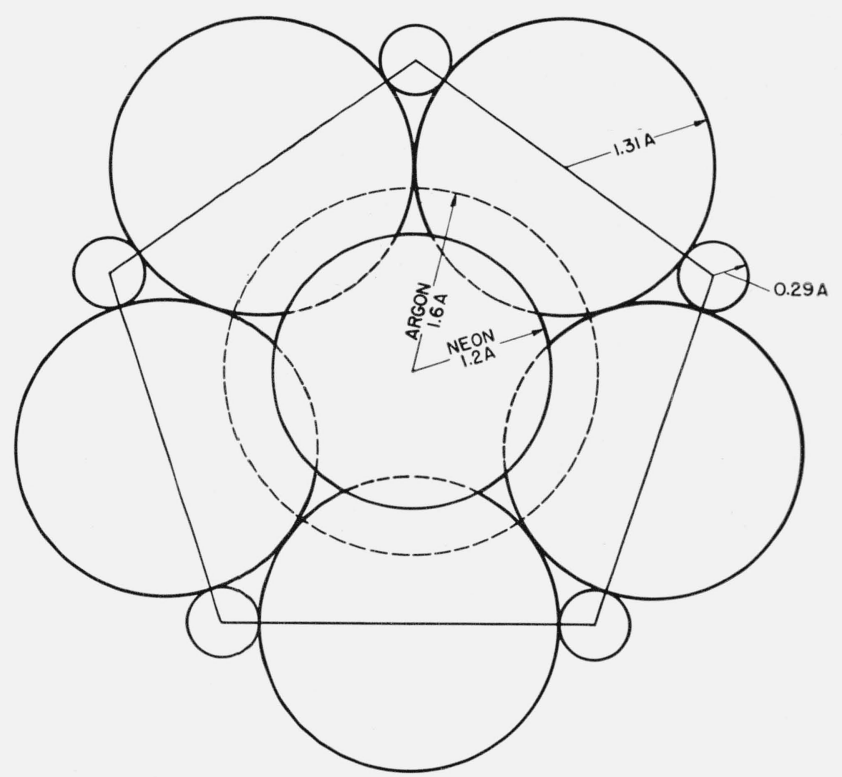

FIGURE 8. Limiting aperture for diffusion of gases through silica glass.

The clear aperture of the pentagonal faces of the vitron elements is comparable in diameter with the neon atom which is the largest that rapidly diffuses in quantity.

$100^{\circ} \mathrm{C}$ are decreased by a factor of $1,000,000$ as the percentage of modifiers is increased from glass to glass. It is here suggested that this difference is caused mainly by the physical presence of nonsilica packed inside the elemental cages of the vitrons. It does not seem necessary to look to the interstices between vitrons as the only channels for permeability in silica glass.

\section{Radial Distribution of Atoms}

All atoms in this model are found to be distributed in accord with published data on the radial distribution of atoms with respect to any one ion in vitreous silica. That is, for very short distances to their nearest neighbors both $\mathrm{Si}$ and $\mathrm{O}$ atoms are so situated that the arrangement is not distinguishable from that formerly assigned to high cristobalite. Warren [16] was a leader in applying the radial-distribution method to the analysis of X-ray diffraction patterns obtained from glasses. The concept of a random network required such treatment instead of the simpler computation of Bragg- $d$ values as is done for crystals. Hartlief [17] also reported such distances for fused silica from X-ray data. More recently, neutron diffraction data for fused silica were treated in this manner by Milligan, Levy, and Peterson [9]; and Weber [18] et al. have reported similar unpublished data on two samples of silica glass, one of "high purity" made by the Corning Glass Company and another of "ordinary" quality. These experimental results are listed in table 2 for comparison with the atomic separations as computed from the model made by the writer. (The scale value of $(\mathrm{Si}-\mathrm{O})=1.60$ is, of course, assumed in the computations.) 
TABLE 2. Radial distribution of atoms in silica glass

\begin{tabular}{|c|c|c|c|c|c|c|c|c|c|c|}
\hline \multirow{3}{*}{\multicolumn{2}{|c|}{ From O to: }} & \multirow{3}{*}{\multicolumn{2}{|c|}{ From Si to: }} & \multicolumn{7}{|c|}{ Distances to neighbor atoms in angstroms } \\
\hline & & & & \multirow{3}{*}{$\begin{array}{c}\text { Proposed } \\
\text { model }\end{array}$} & \multicolumn{3}{|c|}{ Neutrons } & \multicolumn{3}{|c|}{$\mathrm{X}$-rays } \\
\hline & & & & & \multirow{2}{*}{$\begin{array}{l}\text { Mulligan, } \\
\text { Levy, \& } \\
\text { Peterson [9] } \\
1951\end{array}$} & \multicolumn{2}{|c|}{ Weber [19] 1954} & \multirow{2}{*}{$\begin{array}{l}\text { Warren [15] } \\
\text { et al. } 1936\end{array}$} & \multirow{2}{*}{$\begin{array}{c}\text { Hartlief [17] } \\
\quad 1938\end{array}$} & \multirow{2}{*}{ Norman a } \\
\hline No. & Kind & No. & Kind & & & Corning & "Ordinary" & & & \\
\hline $\begin{array}{l}2 \\
6 \\
6 \\
6\end{array}$ & $\begin{array}{c}\mathrm{Si} \\
\mathrm{O} \\
\mathrm{Si} \\
\mathrm{O}\end{array}$ & $\begin{array}{r}4 \\
-4 \\
12 \\
-\end{array}$ & \begin{tabular}{c}
$\mathrm{O}$ \\
\hdashline $\mathrm{Si}$ \\
$\mathrm{O}$
\end{tabular} & $\begin{array}{l}\text { 1. } 60 \\
2.60 \\
3.20 \\
4.00 \\
4.19\end{array}$ & $\begin{array}{l}\text { 1. } 58 \\
\text { 2. } 56 \\
3.02 \\
4.0\end{array}$ & $\begin{array}{l}\text { 1. } 56 \\
\text { 2. } 62 \\
\text { 3. } 32 \\
\text { 3. } 94 \\
4.46\end{array}$ & $\begin{array}{l}1.56 \\
2.71 \\
3.22 \\
\end{array}$ & $\begin{array}{c}1.62 \\
\text { b }(2.65) \\
3.2 \\
4.2 \\
-\end{array}$ & $\begin{array}{c}1.7 \\
\mathrm{~b}(2.7) \\
3.1 \\
4.1 \\
\end{array}$ & $\begin{array}{l}1.64 \\
2.67 \\
3.14 \\
4.17\end{array}$ \\
\hline $\begin{array}{r}3 \\
12 \\
12 \\
12\end{array}$ & $\begin{array}{l}\mathrm{Si} \\
\mathrm{O} \\
\mathrm{O} \\
\mathrm{Si}\end{array}$ & $\begin{array}{r}6 \\
-12 \\
24\end{array}$ & $\begin{array}{c}\mathrm{O} \\
\mathrm{Si} \\
\mathrm{O}\end{array}$ & $\begin{array}{l}4.92 \\
4.99 \\
5.18 \\
5.93 \\
6.14\end{array}$ & $\begin{array}{l}5.1 \\
5.9\end{array}$ & 5.08 & & 5.2 & 5.3 & 5. 25 \\
\hline 12 & o & -...- & $\ldots$ & 6. 79 & 6.6 & ....... & & & 6.3 & 6.5 \\
\hline $\begin{array}{r}12 \\
6 \\
12\end{array}$ & $\begin{array}{l}\mathrm{O} \\
\mathrm{Si} \\
\mathrm{O}\end{array}$ & $\begin{array}{l}12 \\
24 \\
24\end{array}$ & $\begin{array}{l}0 \\
\mathrm{Si} \\
\mathrm{O}\end{array}$ & $\begin{array}{l}7.14 \\
7.15 \\
7.3 \\
7.33 \\
7.71\end{array}$ & 7.4 & & & & 7.5 & \\
\hline $\begin{array}{r}12 \\
3 \\
6 \\
18\end{array}$ & $\begin{array}{l}\mathrm{O} \\
\mathrm{O} \\
\mathrm{Si} \\
\mathrm{Si}\end{array}$ & $\begin{array}{l}12 \\
24 \\
12\end{array}$ & $\begin{array}{l}\mathrm{Si} \\
\mathrm{Si} \\
\mathrm{O}\end{array}$ & $\begin{array}{l}8.04 \\
8.38 \\
8.4 \\
8.54 \\
8.6\end{array}$ & - & c.n & (n...... & an. & $\begin{array}{l}\cdots \\
\cdots\end{array}$ & $\begin{array}{l}\cdots \\
\cdots\end{array}$ \\
\hline .... & $\ldots$ & 4 & $\mathrm{Si}$ & 8.97 & 9.0 & ...... & & & & \\
\hline
\end{tabular}

a Read in 1956 from “uncorrected" curves in Prof. Warren's laboratory. A letter received from N. Norman of Oslo, Norway, just as this paper goes to press, lists his "uncorrected" and still unpublished values as 1.62, 2.62, 3.05, 4.08, and 5.02 .

b Not resolved.

No rattempt is made to compute the angle $\mathrm{Si}-\mathrm{O}-\mathrm{Si}$ from the diffraction data. The departure, $\alpha$, of this angle from $180^{\circ}$ might be estimated by means of the equation

$$
\cos (\alpha / 2)=(\mathrm{Si}-\mathrm{Si}) / 2(\mathrm{Si}-\mathrm{O}) \text {, }
$$

but the precision is much too low, and even for averages there must be residual error because the peak corresponding to the $\mathrm{O}-\mathrm{O}$ distance of $2.6 \mathrm{~A}$ is usually imperfectly resolved, and that makes the reading for Si-Si systematically too low and the computed departures from $180^{\circ}$ too large.

The proposed model agrees with the experimental data of table 2 somewhat better than does a random. network model. A random orientation around bond axes soon leads to indefinite predictions of the radial distances. The first uncertain case is the oxygen to second-oxygen distance. For random orientation there are 18 oxygens that might be found anywhere within the range 4.2 to $5.2 \mathrm{~A}$. The last fixed distance would be silicon to 12 second-silicons at $5.2 \mathrm{~A}$. Thereafter 18 third silicons might vary from 4.9 to 6.5 A from an oxygen, and 36 third oxygens be found anywhere within the same limits of radii from. any silicon. (Incidentally the uncertainties start with nearer neighbors and rapidly become much greater if values other than $180^{\circ}$ be assumed for the angle $\mathrm{Si}-\mathrm{O}$ - Si.) Weber [19] was evidently surprised to find only 6.9 instead of 18 oxygen atoms at $4.46 \mathrm{~A}$ from an oxygen, and he remarks, ". . . A random orientation of these outlying tetrahedra probably causes 1 oxygen of each 3 to be closer in yielding 6 as the number of oxygens at the $\mathrm{O}-2 \mathrm{~d} \mathrm{O}$ distance." In table 2 it will be seen that the proposed model predicts that 6 of these second oxygens should be found at $4.19 \mathrm{~A}$ and 12 of them at $4.99 \mathrm{~A}$, very close to 3 other distances, so that only the high radial density near 5.1 to $5.3 \mathrm{~A}$ is noticed by most observers.

\section{Planar Distribution of Atoms and Values of Bragg-d}

Computations of values of Bragg- $d$ are not usually made for glasses if it is assumed that their structure is random. When a considerable degree of order is assumed, it then becomes pertinent to consider such tests. In contrast with the simplicity of crystal spacings, those in this model are very numerous and multivalued. Within a single dodecahedron, which seems useful as a unit volume, one finds the atoms all distributable in 6 equivalent sets of 7 planes, each set perpendicular to one of the 6 axes of fivefold symmetry. Also, the same atoms are distributable in 10 sets of 11 planes, each set perpendicular to one of the 10 axes of threefold symmetry; and in 15 sets of 13 planes, each set perpendicular to one of the 15 axes of twofold symmetry. Figures 9 and 10 show how the atoms may be projected to locate these three different systems of planes.

Among the very numerous spacings of figures 9 and 10 there are many duplications, and one finds only 31 different possible values of plane separations for a single cage between limits of 0.8 and $4.5 \mathrm{~A}$ and 


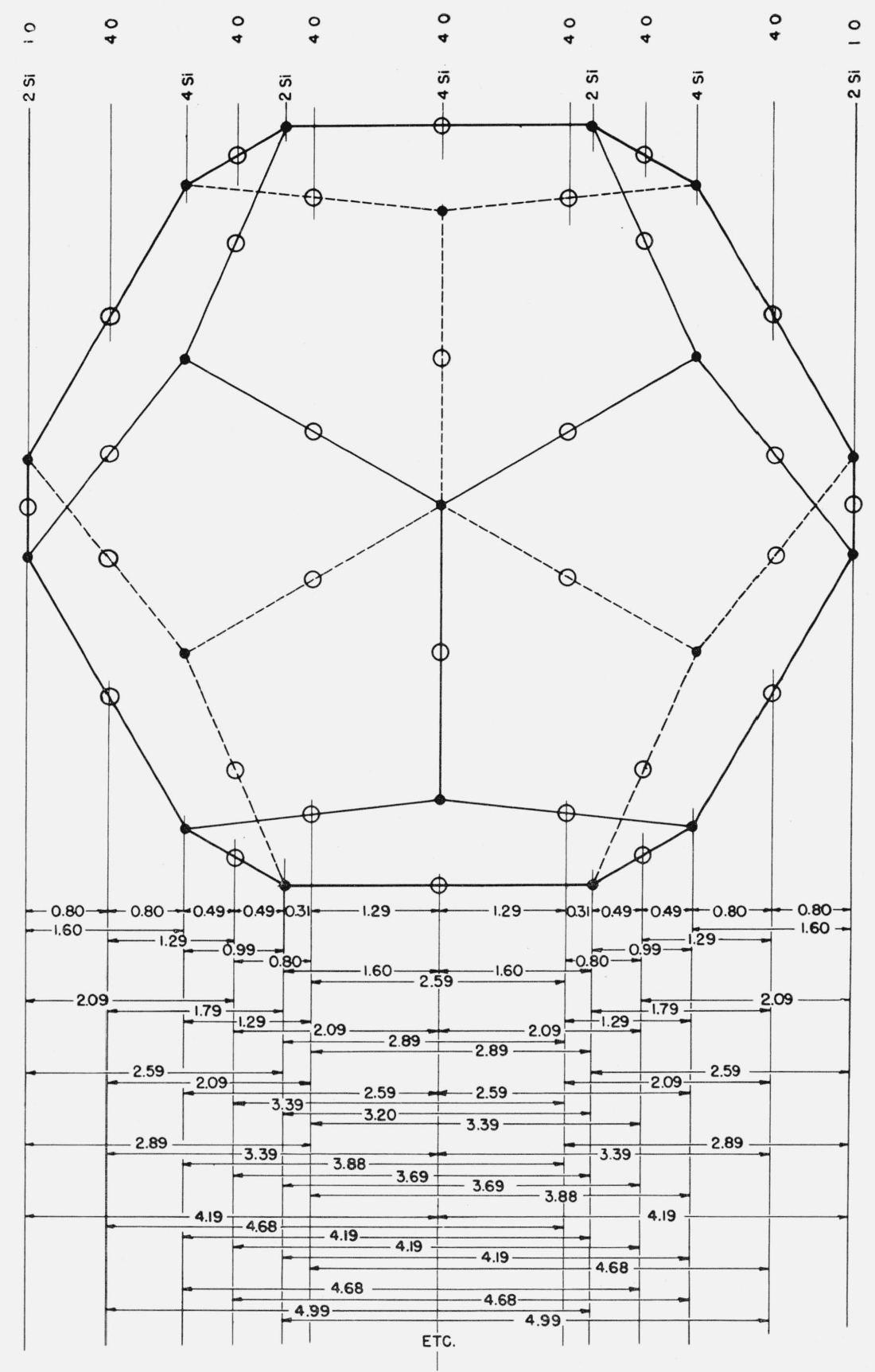

Figure 9. Projection of atom centers of doecahedral element on plane perpendicular to one of its 10 axes of threefold symmetry. The atoms are further projected to determine the spacing of 13 pseudo lattice planes perpendicular to the 15 twotold axes.

considering all three sets of projections. This can be compared with about 35 peaks (or indications thereof) that can be used for computing $d$-values from the curves of scattering of neutrons as found by Weber [18] for a sample that he labels as Corning fused silica; or 18 peaks for a sample called ordinarv fused silica.

Because of the numerous atoms in intervening planes, no X-ray values of Bragg- $d$ should be expected for plane separations exceeding about $3 \mathrm{~A}$, as judged from analysis of the data in figures 9 and
10. Below $3 \mathrm{~A}$ it is estimated by a rough process of atom counting and weighting that about $10 d$-values might be detected by X-ray and electron diffraction, and 6 or 7 are found from such data.

For vitron clusters, as wholes, there are some other possibilities which seem chiefly to be distorted values of the separations as shown in figures 9 and 10 . An example is the $d$-value near $4.3 \mathrm{~A}$ that is not predicted from the model on the basis of a single element but is prominent in X-ray data. In clusters there takes place an overlapping of the vitron ele- 


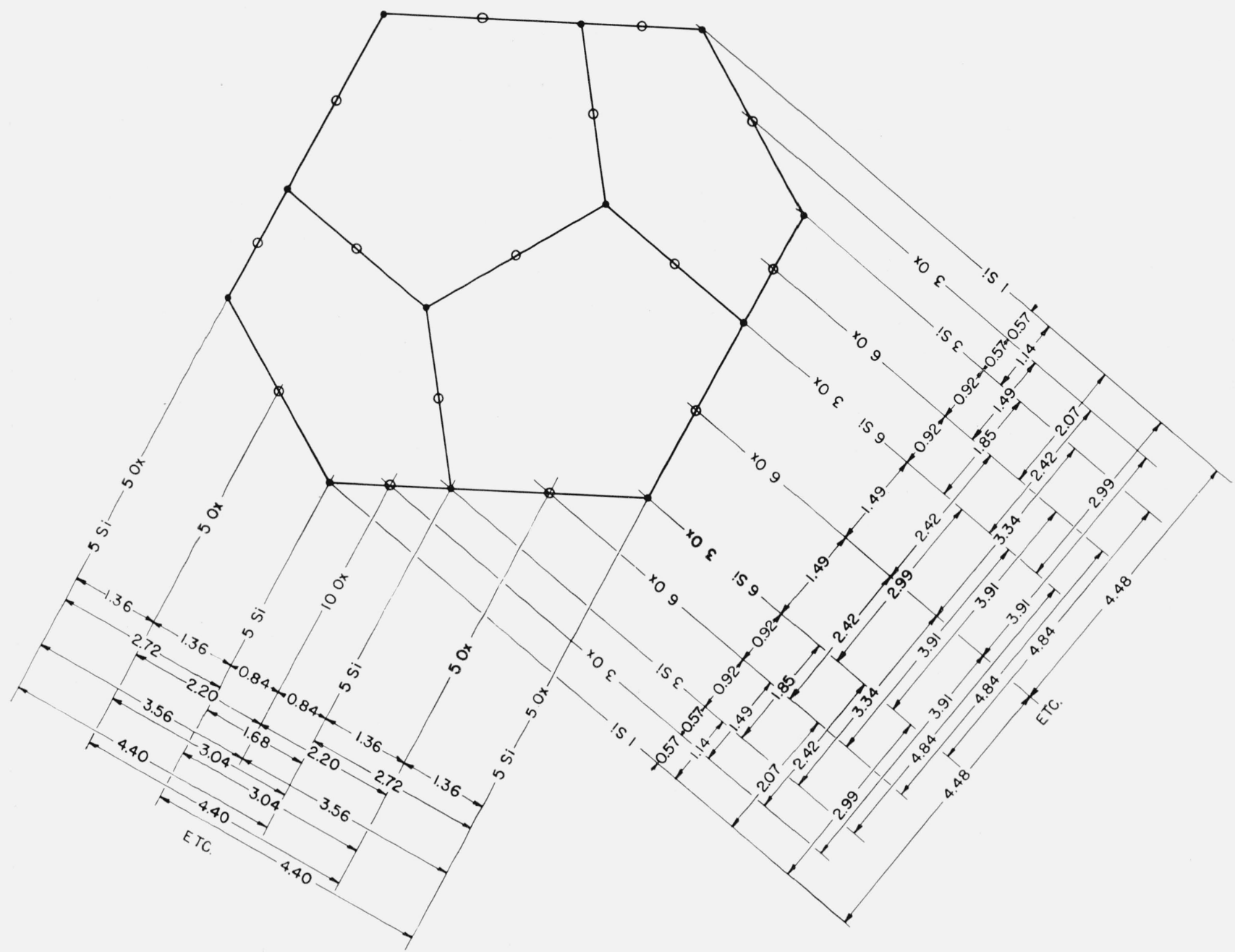

Figure 10. Projection of dodecahedral element on plane perpendicular to one of its 15 axes of twofold symmetry.

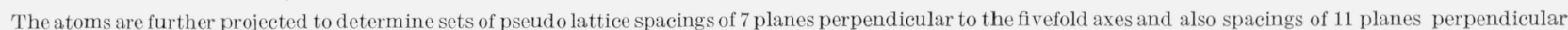
to the threefold axes.

ments. An important case seems to be the overlapping of fivefold and twofold axes, and this was first noticed in a model of the 13-element vitron as viewed transversely to any of its fivefold axes. The distortions are such that approximate coincidence is forced for the $4.19 \mathrm{~A}$ separation along the twofold axes and the $4.40 \mathrm{~A}$ separation along the fivefold axes. The hybrid "planes" are curved with separation varying from $4.40 \mathrm{~A}$ along the principal fivefold axes of the whole vitron to $4.19 \mathrm{~A}$ at distances of something like $6 \mathrm{~A}$ from the principal axis (see figure 11).

In brief, because of the limit of precision in the experimental data one can say only that the number and values of Bragg-d separations predictable from the proposed model agree with the diffraction data about as well as the agreement among different experimenters or for different samples of silica glass. It is suggested, however, that the large number of these distorted pseudo planes has an important effect on the level of observed scatter and the general fuzziness of diffraction patterns.

\section{Potential Flaws and Tensile Strength}

The properties that may logically be inferred from the nature of vitrons, as they have been here defined and described, seem to offer interesting explanations of some of the unusual and not satisfactorily understood properties of silica. For example, in the testing of bulk specimens the actual tensile strength of fused silica (and other silica glasses) is only a fraction of the computed "cohesive" strength. The Griffith [20] crack theory is the usual "explanation," namely, that glass is completely riddled with flaws, but there seems to be no acceptable basis for the existence of the cracks. Stanworth [21] says that it seems as if the entire volume of glass may be permeated with cracks. Cox [22] considers some of the facts as suggestive of crack propagation in an elastic continuum after initiation by a flaw, but on the other hand finds that associated factors lead to an atomic view involving period and energy of vibration and size of ions in order to explain what may be "macroscopic manifestations of the discrete nature of glass." 


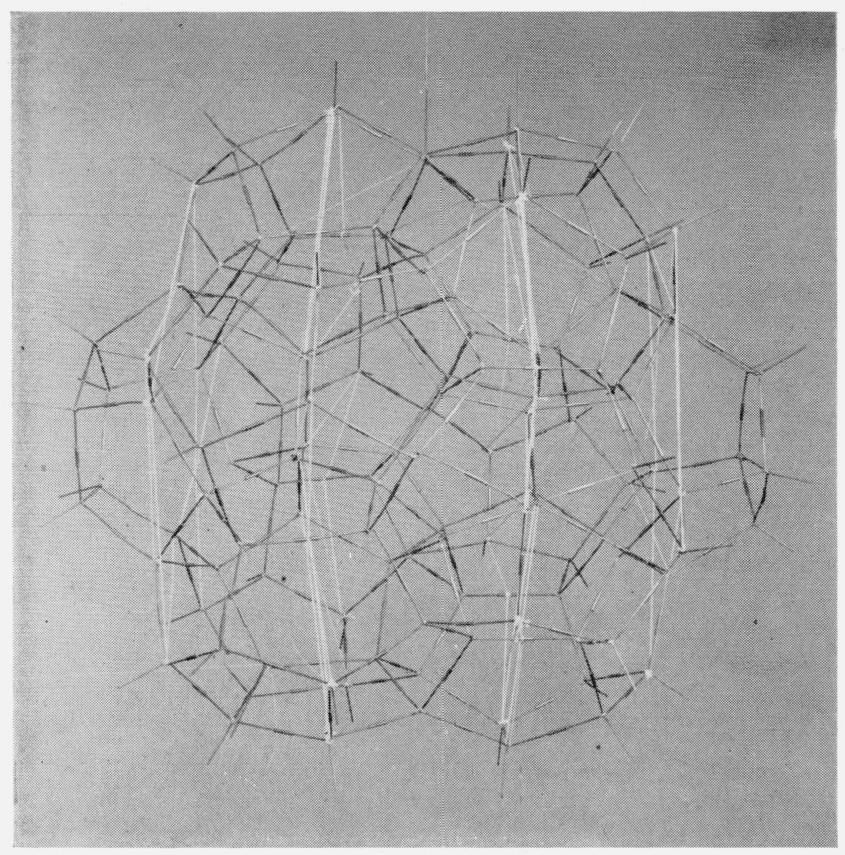

Figure 11. View perpendicular to one of the 6 fivefold axes of symmetry of a 13-element vitron.

Strings show locations of prominent curved or hybrid "planes" in which numer. ous ions are located. The separation of adjacent hybrid planes of like curvature is $4.4 \mathrm{~A}$ along the fivefold axes and $4.2 \mathrm{~A}$ along approximately parallel (secondary) twofold axes at distances of $6 \mathrm{~A}$ from such principal axes. A similar forced approximation to coincidence is found at right and left of center along the 15 axes of twofold symmetry, to which secondary fivefold axes are approximately parallel. These separations of 4.2 and $4.4 \mathrm{~A}$ are of interest because the most prominent diffuse ring commonly observed in both $\mathrm{X}$-ray and electron diffraction patterns indicates a Bragg- $d$ of $4.2 \pm 1 \mathrm{~A}$.

According to the vitron concept, the intrinsic tensions of distortional origin cause weak peripheral bonds that provide a basis for incipient cracks, and there are fewer bonds per unit cross section in the interstitial connective tissues between vitrons than within them. This explains the low glass strength as compared to a medium having bonds of uniform strength uniformly distributed.

Murgatroyd [23] discussed the delayed elastic effects in glass and attributed the effects to gradual yielding of weak bonds. He proposed that the constitution of silicate glasses is such that the binding force between atoms varies from the maximum possible value to a relatively small value, and "regions occur where numerous bonds of the weakest type exist as neighbors." He concluded that "the low strength of massive glass is due to the numerous weak bonds it contains.'

Murgatroyd also mentions the smallness of the difference in density between liquid silica glass and cristobalite, and points out that silica resembles a normal liquid in this respect. He observes that one way in which the great increase in fluidity may be accounted for is "the presence of regions of weak bonds interspersed amongst normally bonded groups of atoms."

On the basis of a continuous random network theory there is no satisfactory evidence that weak bonds would be sufficiently numerous to account for the very great discrepancies between theoretical cohesive strengths and maximum realized tensile strengths of glasses, and especially so for fused silica glass; but the vitron concept, with very numerous bonds that are seriously tensed and interstitial connective tissues where the bond density is low, seems definitely satisfactory in this respect.

Much of the testing of glass for breaking tensile strength has been done on fibers. The values obtained are higher than for tests on samples with large cross sections, and especially so if the fibers are drawn in approved manner and great care taken to avoid damage to their surfaces. If ambient conditions are favorable during drawing and if average results are plotted against diameter of cross section, or formation temperatures as was done by Otto [40], the curves can be extrapolated toward smaller diameter or higher temperature for somewhat higher estimates of the breaking strengths, which however, are still much below expectations from the computed cohesive strengths of 2.5 to $5 \times 10^{6} \mathrm{lb} / \mathrm{in}^{2}{ }^{2}$ for commercial glasses [39].

Considerable attention has been given to reasons for higher breaking strengths of fibers as compared with massive glass. Chilling should introduce compressions in the surface layers and increase breaking: strengths to some extent but this effect must become less important as diameters are decreased because there must be interior compensating tensions. Orientation of structure into threadlike alinements, caused by the drawing process, has been much discussed, but Otto and Preston [48] found little difference in strengths whether by tensile or torsional tests; more recently Otto [40] and Brannan [49] have reported high values of strength on fibers that do not show anisotropy; and Goldstein and Davies [47] did not find anisotropy in silicate glass fibers although it was present in some others. Additional pertinent evidence has been presented by Lynch and Tooley [46], who find that their observed increases in strength (up to $62 \%$ ) by down-drawing under increased load are not eliminated, although materially reduced, after abrasion of the surfaces of the fibers.

The idea of change in either statistical or spatial distribution of types of vitron is not analogous to elongational distortion of a given type of vitron. The stresses and distortions involved may, however, be smaller and thus union with neighbors may be improved. In any event the stress systems would necessarily be balanced on a vitron-volume level, and it would seem that vitrons at and near the surface could more easily meet the requirements for strong unions and attachments with neighbors because of less exacting three-dimensional requirements. This would mean a maximum of strong intervitron connections in all directions near the surface, and a progressively smaller proportion of strong connections inside until the distance from the surface becomes large compared to the vitron size. 


\section{Effects of Localized Stresses on Extensive Properties and Elastic Moduli Above Room Temperatures}

The unusual extensive and elastic properties of silica glass have been so well discussed by Babcock, Barber, and Fajans [6] that some details and many references will be omitted here. In order to explain these peculiar relationships those authors suggest the coexistence of two or more different ionic structures in equilibrium in ratios that vary with temperature and pressure. Also, they consider that the lowtemperature heat capacity, as well as infrared and Raman spectra, may "indicate the coexistence of relatively weak and strong forces."

An experimental curve showing the temperature variations in the modulus of rigidity of fused silica indicates strong thermal variations in stresses within the components of its structure. This modulus decreases from $2^{\circ} \mathrm{K}$ to a minimum near $65^{\circ} \mathrm{K}$, rises to a maximum near $880^{\circ} \mathrm{C}$, and then has an extremely rapid decrease near $1,020^{\circ} \mathrm{C}[24]$. It will be noticed that the minimum near $65^{\circ} \mathrm{K}$ coincides with the minimum for Young's modulus of silica glass, the maximum at $880^{\circ} \mathrm{C}$ is somewhat higher than the similar maximum for Young's modulus (not far from a broad weak minimum in expansion coefficient), and at $1,020^{\circ} \mathrm{C}$ the lower limit of the annealing range has been reached where viscosity approximates $10^{14}$ poises and localized differences in stress are not maintained indefinitely.

It is here suggested that the localized stress systems consist of (1) intratetrahedral attractive and repulsive forces that promote and maintain angular symmetry within the tetrahedra, and (2) the tensed $\mathrm{Si}-\mathrm{O}-\mathrm{Si}$ bonds that make and maintain contact between tetrahedra through the oxygen bridgescontacts that cannot exist without internal distortion in the tetrahedra.

As hot glass cools toward the critical lower limits of the annealing range, the strain response to stress has become decidedly time dependent. For silica glass in particular (free from the complication of modifiers) the repulsive and attractive forces within tetrahedra increase and maintain greater symmetry therein at the expense of greater tensions in the $\mathrm{Si}_{-}-$ $\mathrm{O}-\mathrm{Si}$ bonds between tetrahedra. This necessitates more regular and symmetrical dodecahedra which can obtain only if some connections are broken and interstitial tissues or fissures are extended or widened. This is confirmed by the marked decrease in activation energy of flow (slope of $\log _{10} \eta$ versus $1 / T$ ) for silica glass at temperatures below its annealing range where viscosity increases very slowly above $\log _{10} \eta=13$.

After the initial rapid increase in cohesive forces during cooling near $1,020^{\circ} \mathrm{C}$ has produced increases in the moduli there are slower progressive changes or relaxations in the balanced internal stress systems of vitrons that produce marked but gradual decreases in the moduli but have very little effect on volume. In respect to volume the normal contractions of the units of structure are nearly offset by the expanded channels between vitrons over a long range in temperature. Although these contractions permit some readjustments and relaxations of stresses in the tetrahedra that in turn check the initially excessive fissuring effect, there is still progress in the fissuring (because of increased attraction and consequent increased symmetry within the tetrahedra) so that interstitial (intrachannel) cohesion can decrease slowly and the concurrent increase in intravitron cohesion be negated by the mere existence of the weaker channel interstices.

From the above discussion it is evident that the net coefficients of thermal expansion of silica glass can be very small and nearly constant between $1,000^{\circ}$ $\mathrm{C}$ and room temperatures. Furthermore it is clear that these net coefficients at increased pressure should be larger because the negative components caused by stress-induced fissuring would be correspondingly suppressed by the increase in pressure.

The analysis given also suggests that the compressibility of silica glass should be abnormal and increase with pressure because the tensed bonds in and near the interstitial or channel tissues should aid the applied pressure and do so more effectively as and until the atoms approach their equilibrium positions. This has indeed been observed up to pressures near $36,000 \mathrm{~kg} / \mathrm{cm}^{2}$ where Bridgman [25] found that the abnormal increases in compressibility ceased abruptly and were then followed by decreases, in a normal manner, at higher pressures.

According to the automatically-limited-growth feature of the vitron theory, and to the extent that Bridgman's pressures are equivalent to hydrostatic pressures, his $36,000 \mathrm{~kg} / \mathrm{cm}^{2}$ applied radially to each vitron would seem to substitute directly for a radial compression previously produced or maintained indirectly by tangential tensions of $(36,000 / \sigma) \mathrm{kg} / \mathrm{cm}^{2}$, where $\sigma$ is Poisson's ratio which is near 0.16 for silica glass at room temperatures. Such tangential tensions of $225,000 \mathrm{~kg} / \mathrm{cm}^{2}$ or $3.2 \times 10^{6} \mathrm{lb} /$ in $^{2}$ are in very reasonable agreement with estimates of theoretical cohesive strength. Shand [39], for example, gives 2.5 to $5 \times 10^{6} \mathrm{lb} / \mathrm{in} .^{2}$ for common commercial glasses, and thus this abnormal compressibility observed by Bridgman seems quantitatively to confirm the writer's inference (section 2, above) that vitron growth is limited by the strength of the $\mathrm{Si}-\mathrm{O}-\mathrm{Si}$ bonds.

Moreover it will be realized that the compression produced by a given pressure should be lower at increased temperatures because the process of fissure closing by applied pressures is then applicable only to the lowered level of fissuring that can exist at the higher temperatures. This accords with observations and measurements by Birch and Dow [26] from room temperatures to $400^{\circ} \mathrm{C}$ on fused silica and a Pyrex glass. 


\section{Internal Friction and Elastic Constants at Low Temperatures}

A study of thermal effects on elastic moduli at low temperatures invites consideration of the internal friction evidenced by the attenuation of ultrasonic waves observable from $2^{\circ}$ to $190^{\circ} \mathrm{K}$ and having very broad maxima near 30 to $50^{\circ} \mathrm{K}$ depending on the frequencies used $(60 \mathrm{kc}$ to $20 \mathrm{Mc} / \mathrm{sec})$.

Such friction effects are very small in quartz and observable only with care. In fused silica they were observed by Marx and Sivertsen [38], by McSkimin [36], and by Fine et al. [37] before their more detailed observation and discussion by Anderson and Bömmel [24]. Fine's data show minima in Young's modulus, torsion modulus, and Poisson's ratio near $65^{\circ} \mathrm{K}$ and a very broad maximum in compressibility near $65^{\circ} \mathrm{K}$. The Anderson and Bömmel data show a minimum in rigidity at $65^{\circ} \mathrm{K}$ for $66 \mathrm{kc}$ and near $75^{\circ} \mathrm{K}$ for the 20 -Mc curve. The last named authors find that the temperature and frequency behavior suggest a structural relaxation with a distribution of activation energy averaging 1,030 cal/mole. Further they find that the absorption is largely due to a shear elastic wave and therefore to a mechanism that does not primarily tend to cause fluctuations in density; and that the relaxation strength is small, only a fraction of all particles contributing, as shown by the small increase (about 3\%) in shear modulus from the minimum value to that at $4^{\circ} \mathrm{K}$.

For discussing these results in relation to vitron theory it is convenient to start near room temperatures where there is a noticeable decrease in coefficient of thermal expansion. This may mean merely that the rate of expansive fissuring has fallen definitely below that of normal contraction and continues so until minimum volume is reached near $190^{\circ} \mathrm{K}$. Here the above described internal friction begins very gradually to be detectable by attenuation of acoustic waves, and the compressibility after remaining relatively constant over an interval of $\pm 75^{\circ}$ near room temperatures resumes an abnormal climb as temperatures are lowered. It is here suggested that because of continuous and gradually increasing intravitron contraction some of the bonds yield in and near the interstitial channels between vitrons. This would provide limited numbers of less well bound oxygen for the sort of transverse vibrations visualized by Anderson and Bömmel, and do so in ever increasing number until the whole process is checked by the near contacts and strong repulsive forces at very low temperatures. Apparently lower temperatures are necessary to check the absorbing vibrations than those required to start closure of the fissures and decrease compressibility. At the lowest temperatures of observation it will be noticed that the rigidity increases and compressibility decreases as is normal on approaching absolute zero. The greater slopes on the low-temperature side of all of these curves may indicate that a normal balance between repulsive and attractive forces is effectively reached at the temperatures of their respective maxima or minima near $65^{\circ} \mathrm{K}$.

\section{Vitron Theory and Heat Treatments}

According to the theory of intrinsically stressed vitrons, after fused quartz is repeatedly heated and cooled in treatments that reach $900^{\circ}$ or $1,000^{\circ} \mathrm{C}$, these repeated heat treatments should slightly reduce the localized stresses present within the vitrons and result in small volume changes at a given room temperature as compared with previous measurements at the same temperature. Such changes should be unidirectional (expansions) and permanent, that is not reversible by subsequent heat treatments in comparable temperature ranges. Considerable evidence of this has been found in the course of annealings and in measurements of the thermal expansion [42] of vitreous silica. Possibly some effects of this sort should be considered in connection with the results published by Saunders and Tool [43] on Pyrex glasses.

Such irreversible heat effects, or effects reversible only after more fundamental heat treatments at much higher temperatures, should be less and less evident as the nonsilica content of glasses is increased, and they were not of noticeable magnitude in the results reported by Tool [44] and associates on glasses other than Pyrex.

At very high temperatures in liquid silica the stresses incident to vitron growth produce strains and distortions easily, and there is no rigidity of tetrahedral structure sufficient to resist the tendency for dodecahedra to unite and fill space with a minimum of interstices. Upon cooling and approach to the solidification region, even slight trends toward greater symmetry within tetrahedra lessen the pliability of dodecahedra, create a few broken bonds, and in general form or widen interstitial tissues or fissures. This expansive effect may exceed the normal contractive effect and yield a small net negative coefficient of expansion such as was observed by Douglas and Isard [27] between $1,000^{\circ}$ and $1,500^{\circ} \dot{\mathrm{C}}$. Small spheres of vitreous silica had previously been quenched by Salmang and von Stoesser [28] from high temperatures into water and they had announced the existence of a minimum density for this glass between $1,200^{\circ}$ and $1,800^{\circ} \mathrm{C}$.

These positive changes in density of silica glass with increase of temperature in and above its annealing or "transformation range" are very small, say $+1 \times 10^{-5} / \operatorname{deg} \mathrm{C}$, and contrast with negative values of from -16 to $-46 \times 10^{-5} / \mathrm{deg} \mathrm{C}$ that were found by Tool [44] for various silicate glasses in their annealing ranges. These larger and negative changes are attributable, according to the writer, almost entirely to the silica network but the cause may be very different. It is suggested by the writer [45] that there is an inherent temperature dependence of the silicon-oxygen-silicon bond angle that is locked in a semi-invariant or metastable state in pure fused silica, but is free to operate in silicate glasses in proportion as they contain modifiers. The result is a limited, temperature dependent, and reversible degree of folding or collapse of the network structure. 


\section{Specific Volumes of Soda Silicate Glasses}

A useful feature of vitron theory is the degree in which it may be quantitatively applied in studies of the properties of simple binary glasses as functions of composition. Applications of the vitron concept to specific volume, viscosity, volatilization, and electrical resistivity of glasses are being made and data on infrared spectra are being studied. It is found that the proposed ideas accord with many such data for fused silica and for simple alkali-silicate glasses. These results will be given in another paper with emphasis on property-composition curves.

However, one such application to binary glasses can be readily summarized here. Since the number of cages in $\mathrm{R}_{2} \mathrm{O}$ silicate glasses is proportional to $S / 5$ (where constituent proportions $R+S=1$ ), it follows that the proportions of $\mathrm{R}_{2} \mathrm{O}$ corresponding to integral numbers of cations per cage, $R_{h}$, are readily computed as $R=R_{h} /\left(R_{h}+10\right)$. At such integral steps or degrees of saturation (and supersaturation) of the cages it seems probable that some evidences of changes in rate might be found on curves of property versus composition. Huggins [35] has already studied existing data of volume-composition curves for soda-silicate glasses as published by Glaze [41] et al., and found evidence of special points at $\mathrm{Si}$ to $\mathrm{O}$ ratios of $0.437,0.40,0.38,0.36,0.345$, and 0.333 which are now found to correspond precisely to values of 3,5 , $6,8,9$, and 10 for $R_{h}$ according to vitron theory. This good agreement between vitron theory and the results by Huggins from his investigation is shown in further detail in table 3 .

TABLE 3. Application of vitron theory to specific volumes of soda-silicate glasses

\begin{tabular}{|c|c|c|c|c|c|c|}
\hline \multirow{2}{*}{\multicolumn{2}{|c|}{$\begin{array}{l}\text { Molar } \\
\text { composition }\end{array}$}} & \multirow{3}{*}{$\begin{array}{l}\text { Holes } \\
\text { S/5 }\end{array}$} & \multirow{3}{*}{$\begin{array}{c}\text { Cations } \\
\text { per cage } \\
R_{h}\end{array}$} & \multicolumn{3}{|c|}{ Special ratios of silicon to oxygen } \\
\hline & & & & \multirow{2}{*}{$\begin{array}{c}\text { Computed } \\
\text { from vitron } \\
\text { model }\end{array}$} & \multicolumn{2}{|c|}{ Found by Huggins } \\
\hline $\mathrm{Na}_{2} \mathrm{O}$ & $\mathrm{SiO}_{2}$ & & & & 1940 & 1954 \\
\hline $\begin{array}{l}0.00 \\
.091 \\
.167 \\
.231 \\
.286\end{array}$ & $\begin{array}{l}1.00 \\
0.909 \\
.833 \\
.769 \\
.714\end{array}$ & $\begin{array}{r}0.200 \\
.182 \\
.167 \\
.154 \\
.143\end{array}$ & $\begin{array}{l}0 \\
1 \\
2 \\
3 \\
4\end{array}$ & $\begin{array}{l}0.50 \\
.476 \\
.454 \\
.435 \\
.417\end{array}$ & .435 & .437 \\
\hline $\begin{array}{l}.333 \\
.375 \\
.411 \\
.444 \\
.474\end{array}$ & $\begin{array}{l}.667 \\
.625 \\
.589 \\
.556 \\
.526\end{array}$ & $\begin{array}{l}.133 \\
.125 \\
.118 \\
.111 \\
.105\end{array}$ & $\begin{array}{l}5 \\
6 \\
7 \\
8 \\
9\end{array}$ & $\begin{array}{l}.400 \\
.385 \\
.371 \\
.357 \\
.345\end{array}$ & $\begin{array}{c}\mathrm{a}(.364) \\
.345\end{array}$ & $\begin{array}{l}.40 \\
(.375) \\
(.357)\end{array}$ \\
\hline $\begin{array}{l}.500 \\
\text { etc. } \\
.630\end{array}$ & $\begin{array}{c}.500 \\
.370\end{array}$ & .100 & 10 & .333 & $\begin{array}{l}(.333) \\
.27\end{array}$ & .333 \\
\hline
\end{tabular}

a Ratios in parentheses were less prominent or seem to be given less weight by Huggins.

\section{Concluding Remarks}

Study of this model for silica glass emphasizes two pertinent characteristics. First, it has a type of order with many axes and numerous and varied spacings of quasi lattice planes that cannot grow into a sizable crystal, and second, it has distortions and stresses and consequent curvature of the lattice planes. Because it has been shown that this model is consistent with known data on density, differential diffusion of gases, interatomic distances, low tensile strength, unusual thermal and pressure effects on volume, internal friction at low temperatures, and specific volumes of soda-silicate glasses, a new concept should be considered for general study of the glassy state: A small stressed cluster of definitely arranged but slightly distorted elemental groups or cages (such as pentagonal dodecahedra) that in turn are composed of smaller and more nearly regular stable structural units (such as tetrahedra), all of which as a system tends to form at high temperatures in a melt and have an approximate but not exact noncrystal symmetry (such as fivefold) and thus be capable of limited but not extensive continuous growth. Such a cluster may appropriately be called a VITRON in order to distinguish it definitely from a crystallite, which can increase in size without limit. Among the member ions and in connective tissues between the vitrons there will exist a wide distribution of bond strengths and some variation in angles between valence directions that can account not only for a range of melting points but for similar phenomena indicative of ranges in activation energies. The known high energy of dissociation of $\mathrm{SiO}_{2}$ linkages $(106 \mathrm{kcal} / \mathrm{mole}$, an energy which is many times the mean energy of agitation at most industrial temperatures), indicates that vitrons are not necessarily completely broken up into tetrahedra even at temperatures far above fusion.

It would seem that the vitron concept should be welcomed by those who still regard a modified crystallite theory with favor. It is not difficult to visualize these very small submicroscopic vitrons (say 1 to 54-cages, approximately 9 to $30 \mathrm{~A}$ in total diameter) partially united to each other through common faces and also connected by other $\mathrm{Si}-\mathrm{O}-\mathrm{Si}$ bonds or "oxygen bridges," similar to those that unite the tetrahedra within a vitron, and thus forming a structure approximately filling space with intervening connective tissues that vary in width with temperature and degree of existing localized stresses. Considering their various multiple axes, the vitrons could, almost by chance, be positioned to present more or less equivalent orientations regardless of intervening tissues or fissures. This simple but fundamental concept of connected vitrons introduces more than short-range ordered arrangement and thus something that proponents of the crystallite theory have demanded. A quantitative interdistribution of stresses between elements of a vitron, and perhaps between vitrons, helps to explain the remarkable continuity of properties as a function of temperature through, during, and even above the melting range - something that, according to Peychès [29], a mere distribution of sizes and shapes does not satisfactorily explain.

Also, the intrinsic properties of a vitron, including numerous lattice planes, a distribution of stresses among its members, and curvature of the lattice planes, can account for much of the observed 
broadening of diffraction rings without large percentages of voids such as the crystallite theory seemed to require.

The network theory is modified and strengthened by the vitron concept because the existing troublesome requirement for first-order randomness in the network is thereby eliminated - a randomness that is not entirely compatible with some of the wellestablished properties of glasses and is being challenged by electron and neutron diffraction data which evidence greater order than did X-ray data. Further, the idea of unbroken continuity is replaced by the much more useful concept of a quasi-discrete or modulated continuity.

In addition, the vitron concept readily diverts excessive attention from the old idea that glass is merely supercooled liquid. Thus it accords well with certain thermodynamical and other considerations that seem to have led Parks and Huffman [30], and later Berger [31], to suggest that glass is a fourth state of matter resembling but definitely differing from the crystalline state rather than a twilight zone intermediate between liquids and crystals. Because in some respects the glassy state differs so very little from the crystalline state, it has always been difficult to accept as fully satisfactory the undercooled liquid ideas or to account for the stability and reproducibility of definite degrees of major disorder in networks in the absence of coercive fields. An important difference between the present vitron concept and Berger's ideas, as usually understood, is that the vitron or glassy state forms at very high temperatures in the melt rather than at or near annealing or softening temperatures.

The vitron concept of stressed clusters of cages having a dodecahedral arrangement of pentagonal rings of slightly deformed tetrahedra, may be applicable to other than silicate glasses. For boric oxide glass with boron in four-coordination state, it can be shown that a reasonable density is given by such an arrangement starting with nearest-neighbor distances to accord with X-ray evidence.

In the broader field of glasses in general, it is possible that the vitron concept (with other noncrystal symmetries) may open new vistas for study and investigation. Perhaps it will suggest comparable concepts relating to the constitution of liquids and solutions. Particularly in the field of rheology, it may prove useful and possibly it may relate to crystallinity in the field of high polymers. It would seem that some writers have felt the need for and referred to somewhat similar concepts. Machatschki [32] speaks of "precrystalline" arrangements; Debye and Menke [33] describe a "quasicrystalline" arrangement instead of a disordered atomic distribution in liquid mercury; and Matossi [34] infers that in fused silica there are regions of distorted order separated by places of still greater lattice distortion. Aside from an investigation of its possible applications, the idea seems to call for a mathematical study of the various classes of symmetry that are adapted to nonerystal-forming arrangements of matter in space, with a degree of periodic order and regularity roughly comparable to but much more limited than those found in crystals.

\section{Appendix}

\subsection{Union and Attachment Between Vitrons}

Some possibilities concerning the growth and uniting of clusters, or vitrons, may warrant examination in more detail. Consider a sphere inscribed in a regular pentagonal dodecahedron. It can be surrounded by 12 equal spheres tangent to the first on each of the 12 pentagonal faces to form a cluster of 13 spheres of which only the central sphere touches more than one other. In the next shell one may add 12 spheres along diameters through the 12 of the first shell and also 20 on diameters through the inner sphere and through the 20 apices of the original polygon. The cluster is now composed of 45 spheres. This is a packing that is regular but uniquely referable to only one definite center.

In this type of packing of rigid incompressible spheres or cages the density decreases toward the periphery because of voids between cages as the cluster grows. If the cages are deformable, however, there can be a small but limited growth of such a system with sufficient distortion of cages in the outer shells to close the interstices and form a cluster approximating uniform density. In the case of dodecahedrons of silicon and oxygen, the chemical bond between these elements is very strong and these are the forces that tend to maintain vitron structures after their formation at high temperatures. The extent to which they can be maintained is, however, definitely limited. Important possibilities in this type of vitron are clusters of 1 , or 13 , or 45 dodecahedra.

In grouping dodecahedral elements to form vitrons one can arrange them, as just described, around (1) a central elemental volume, (2) a common face of 2 elements, (3) a common edge of 3 elements, or (4) a common apex of 4 elements. The first type permits the nearest approach to spherical clusters. The second is perhaps the least spherical; it can lead to chain structure. The third can manifest a cylindrical tendency; also it seems adapted to sheet or laminated structure. The fourth is somewhat tetrahedral but the surfaces and edges of the whole cluster are so decidedly curved that sphericity is approximated as the vitron grows.

In studying these types of arrangement, the characteristics of attachable and unitable vitrons were computed for several more or less spherical clusters consisting of from 1 to 54 elements of volume. The results are summarized in table 1 . In addition to the tabulated characteristics of vitrons in table 1 , there are other factors that affect their degree of union or attachability. The single element as tabulated can unite any two clusters each of which has one free penta face. There are other useful reduced single elements such as $\left(\mathrm{Si}_{9} \mathrm{O}_{18}\right)_{2 \mathrm{~F}}^{9+}, 9-$ which can be joined by union to 2 adjacent penta faces, as presented by a 2 -cluster, to form a 3-cluster; and $\left(\mathrm{Si}_{8} \mathrm{O}_{16}\right)_{3 \mathrm{~F}}^{8+, 8-}$ 
which is unitable to 3 adjacent faces, as presented by a 3-cluster, to form a 4-cluster vitron, etc.

A dual element as tabulated can unite with one single element as reduced for adjacent-2-face attachability and to one single element reduced to adjacent3 -face attachability, to form a 4-element cluster as tabulated; that is $1\left(\mathrm{Si}_{20} \mathrm{O}_{40}\right)+1\left(\mathrm{Si}_{9} \mathrm{O}_{18}\right)+1\left(\mathrm{Si}_{8} \mathrm{O}_{16}\right)=$ $1\left(\mathrm{Si}_{37} \mathrm{O}_{74}\right)^{20+, 20-}$. A reduced dual element that is unitable to two adjacent faces is $\left(\mathrm{Si}_{19} \mathrm{O}_{38}\right)_{2 \mathrm{~F}}^{19+, 19-}$.

A triple element cluster as tabulated presents 3 convex 4 -faces, or 2 reentrant 3 -faces plus 3 convex 2 -faces, and can unite clusters presenting correspondingly opposite combinations of penta faces.

The tabulated 4-element vitron can, among other possibilities, be intermediate (that is form or grow) between 4 clusters each presenting a reentrant 3 -face.

The 5-element vitron can unite or have attached to it 2 small clusters each with reentrant 3 -face plus 3 small clusters each with reentrant 2 -face.

The 7-element cluster might unite or have attached to it 5 small clusters each with reentrant 2 -face.

The 13-cluster vitron is very nearly spherical. It is directly and fully unitable through its 12 free faces; or it can accept unions simultaneously at 8 of the 20 places where it has reentrant 3 -face combinations. A few oxygen connections are also available.

The 14-element vitron presents 12 places of reentrant 4-face and a few opportunities for connectibility through oxygens; or it presents convex 2 -face possibilities of union in 6 places, together with added attachability through oxygens.

The 26-element vitron is directly unitable on each of 12 faces and has added attachability through oxygen.

The 45-element vitron is the largest of the spherical or element-center type that has been studied. It is directly unitable through each of 12 penta faces and also attachable through 20 oxygens at places equally distributed over the vitron surface.

The 54-element tetrahedral vitron is unique among those in table 1 in that it presents no penta faces for union with other vitrons. All connections must be through oxygen at 4 triple edges, 12 double edges, and 12 single edges.

\section{2. "Unit Cell" of Vitreous Silica}

The symmetry within vitrons of limited size has different aspects for the different arrangements. For type 1 clusters with a central element there is a center of symmetry and the whole vitron has, basically, all of the axes that were mentioned in section 2 in describing a dodecahedral element (see fig. 7); also there are quasi-reflecting planes similar to those for single elements. It is useful, in attempting to discuss the concept of a "unit cell" for vitreous silica, to note that it is possible to select 3 mutually perpendicular axes running through oxygen atoms and intersecting at the center of an element. As one travels along any of these orthogonal axes of a type 1 cluster, one proceeds 4.19 A from origin to first oxygen, and $4.91 \mathrm{~A}$ further to first silicon, then orients $90^{\circ}$ around the axis and proceeds $4.91 \mathrm{~A}$ to second oxygen, and then $4.19 \mathrm{~A}$ to center of second elemental cage. The second element, however, is at $90^{\circ}$ with the element of origin and one must repeat the four above-mentioned steps to arrive at an element center apparently identical with the origin (but in reality at $180^{\circ}$ therewith). In other words the unit cell in the sense used in crystallography might seem to be $36.4 \mathrm{~A}$ on each edge, if the structure could grow to such an extent. Such a cell would contain $960 \mathrm{SiO}_{2}$. Apparently, one-eighth of this cell with edge of $18.2 \mathrm{~A}$ and containing $120 \mathrm{SiO}_{2}$ might be representative of the structure if suitable orientations and inversions are made.

The estimate of a unit cell just given does not seem satisfactory, however, because along axes parallel to, but somewhat displaced from, the principal axes the repeat distances are not always $36.4 \mathrm{~A}$. Other repeat distances of 14.26 and $24.34 \mathrm{~A}$ are easily found.

If vitrons of type 4 with silicon as a center are considered, it is obvious that there are four axes equally distributed in space and making angles of $109^{\circ} 28^{\prime}$ with each other as in a tetrabedron. Along any of these axes of a cluster of type 4, one proceeds $1.60 \mathrm{~A}$ from origin to first oxygen, $1.60 \mathrm{~A}$ to first silicon, 8.97 to second silicon, then orients $60^{\circ}$ around the axis and proceeds to repeat these 3 steps in the same order to arrive at a silicon apparently identical with the origin (but in reality at $120^{\circ}$ therewith). The apparent repeat distance is $24.34 \mathrm{~A}$.

The vitron of type 3 with a common edge and oxygen at its center, has a principal axis with a repeat distance of $24.34 \mathrm{~A}$, numerically equal to that just found for the tetrahedral axes of type 4 vitrons. Perpendicular to the principal axis there are three axes at $120^{\circ}$ with each other. Along each of these the repeat distance is $36.4 \mathrm{~A}$, numerically equal to that found for the orthogonal axes of type 1 vitrons.

More complicated is the vitron of type 2 with center in a face. Here one has a principal axis and 2 groups of 5 axes each in the plane of the central or common face. Along the principal axis, perpendicular to the central face, one proceeds $7.13 \mathrm{~A}$ to the center of the opposite face, then orients $36^{\circ}$ and proceeds $7.13 \mathrm{~A}$ to a face center that appears as did the origin (but in reality at $72^{\circ}$ therewith). The apparent repeat distance is $14.26 \mathrm{~A}$. For one group of 5 axes, through the 5 oxygens of the central face, the repeat distance is $36.4 \mathrm{~A}$; and for the other group, through the 5 silicons, the repeat distance is also $36.4 \mathrm{~A}$.

The repeat distance of 36.40 A along a two-fold axis through an element center (type 1) must be multiplied by 2 to reach an element center identical with the origin in true orientation; the repeat distance of $24.34 \mathrm{~A}$ along a three-fold axis through a silicon center (type 4) must be multiplied by 3 to reach a silicon identical with the origin in true orientation; and the repeat distance of $14.26 \mathrm{~A}$ along a five-fold axis through a face center (type 2) must be multiplied by 5 to reach a face center identical with the origin in true orientation. The average of these 3 estimates gives the true repeat distance for 
the proposed structure of vitreous silica along any of its multiple axes as 72.4 A and the corresponding cell would contain $7680 \mathrm{SiO}_{2}$. This can be interpreted as the size of the unit cell of vitreous silica that would be found if the structure were capable of growing to such an extent.

\section{References}

[1] J. T. Randall, H. P. Rooksby, and B. S. Cooper, Z. Krist. \%5, 196 (1930; Nature 125, 458 (1930)

[2] C. W. Parmelee, G. L. Clark, and A. E. Badger, J. Soc. Glass Technol. 13, 285, 290 (1929).

[3] W. H. Zachariasen, J. Am. Chem. Soc. 54, 3841 (1932).

[4] B. E. Warren, Z. Krist. 86, 349 (1933) ; 89, 481 (1934); J. Am. Ceram. Soc. 17, 249 (1934); Phys. Rev. 45, 657 (1934).

[5] W. A. Weyl, J. Soc. Glass Technol. 35, 421 (1951).

[6] C. L. Babcock, S. W. Barber, and K. Fajans, Ind. Eng. Chem. 46, 161 (1954).

[7] Sam Spinner, J. Am. Ceram. Soc. 39, 113 (1956).

[8 Edward Melkonian, Phys. Rev. 76, 1749 (1949).

[9] W. O. Milligan, H. A. Levy, and S. W. Peterson, Phys. Rev. 83, 226 (1951)

[10] L. C. Hoffman and W. O. Statton, Nature 176, 561 (1955).

[11] W. L. Bragg, The structure of silicates (Leipzig, 1930).

[12] F. J. Norton, J. Am. Ceram. Soc. 36, 96 (1953).

[13] E. Poncelet, Verres et Réfractaires ?, 208 (1948).

[14] B. E. Warren, J. Appl. Phys. 8, 645 (1937).

[15] N. Valenkov and E. Poray-Koshitz, Nature 13\%, 273 (1936).

[16] B. E. Warren, H. Krutter, and O. Morningstar, J. Am. Ceram. Soc. 19, 202 (1936).

[17] G. Hartlief. Z. anorg. u. allgem. Chem. 238, 368 (1938).

[18] R. M. Delaney, P. J. Persiani, and A. H. Weber, Technical Report No. 1-Research Program on the Neutron Diffraction Study of the Structure of Glasses. No-

vember 1, 1954. Dept. of Army Project 5B99-01-004.
[19] Weber, et al, Table IV, p. 33 of Report cited in literature reference No. 18.

[20] A. A. Griffith, Trans. Roy. Soc. (London) [A] 221, 163 (1920).

[21] J. E. Stanworth, Physical properties of glass, p. 82 (Oxford, Eng. 1950)
[22] S. M. Cox, J. Soc. Glass Technol. 32, 128 (1948).

[23] J. B. Murgatroyd, J. Soc. Glass Technol. 32, 291 (1948)

[24] F. Horton, Trans. Roy. Soc. (London) [A] 204, 407 (1905); O. L. Anderson and H. E. Bömmel, J. Am. Ceram. Soc. 38, 126 (1955).

[25] P. W. Bridgman, Am. J. Sci. 237, 7 (1939).

[26] F. Birch and R. B. Dow, Bull. Geol. Soc. Amer. 47, 1235 (1936)

[27] R. W. Douglas and J. O. Isard, Nature 175, 747 (1955).

[28] H. Salmang and K. von Stoesser, Glastech. Ber. 8, 479 (1930).

29] Ivan Peychès, Verres et Réfractaires 8, 181 (1954).

[30] G. S. Parks and H. M. Huffman, Science 64, 364 (1926).

[31] E. Berger, Zeits. techn. Physik 12, 344 (1931).

[32] F. Machatschki, Radex-Rundschau.p. 76 (Radenthein, Austria, 1952).

[33] P. Debye and H. Menke, Physik. Z. 31, 797 (1930).

[34] F. Matossi, Z. tech. Phys. 18, (12), 585 (1937).

[35] M. L. Huggins, J. Opt. Soc. Amer. 30, 421 (1940); J. Phys. Chem. 58, 1145 (1954).

[36] H. J. Meskimin, J. Appl. Phys. 24, 988 (1953).

[37] M. E. Fine, H. Van Duyne, and Nancy T. Kenney, J. Appl. Phys. 25, 402 (1954).

[38] J. W. Marx and J. M. Sivertsen, J. Appl. Phys. 24, 81 (1953)

[39] Errol B. Shand, J. Am. Ceram. Soc. 37, 572 (1954).

[40] Wm. H. Otto, J. Am. Ceram. Soc. 38, 123 (1955).

[41] F. W. Glaze, J. C. Young, and A. N. Finn, BS J. Research 9, 799 (1932) RP507.

[42] W. Souder and P. H. Hidnert, Sci. Papers NBS 21, 21 (1926) S524.

[43] J. B. Saunders and A. Q. Tool, BS J. Research 11, 807 (1933) RP626.

[44] A. Q. Tool, L. W. Tilton, and J. B. Saunders, J. Research NBS 38, 519 (1947) RP1793.

[45] L. W. Tilton, J. Soc. Glass Technol. 40, T338 (1956).

[46] E. D. Lynch and F. V. Tooley, J. Am. Ceram. Soc. 40, 107 (1957).

[47] M. Goldstein and T. H. Davies, J. Am. Ceram. Soc. 38, $223(1955)$

[48] W. H. Otto and F. W. Preston, J. Soc. Glass Technol. 34, T63 (1950).

[49] R. T. Brannan, J. Am. Ceram. Soc. 36, 230 (1953).

[50] Charles Kittel, Phys. Rev. 75, 972 (1949).

Washington, March 20, 1957. 